\title{
Aventurando utopías, describiendo horizontes. Reseña del libro: Formación docente en Chihuahua, I824-1940
}

\author{
Adventuring utopias, describing \\ horizons. Book Review: Teacher Training in \\ Chihuahua, I824-1940
}

Juan Tenorio Urbina*

* Profesor de la Universidad Pedagógica Nacional del Estado de Chihuahua, Unidad Chihuahua, México. Es Doctore en Educación Centrado en Investigación por la Facultad de Filosofía y Letras de la Universidad Autónoma de Chihuahua. Algunas de sus publicaciones son: El consumo musical en la formación de estudiantes de licenciatura en intervención educativa (2017), Aprendizaje invertido apoyado por las TIC (2015), Propedéutica para una Filosofia de la Educación con Tecnologías de la Información y Comunicación, entre otras. Sus temas de interés son Historia y Filosofía de la Educación. Correo electrónico: jtenorio@upnech.edu.mx

(D) https://orcid.org/0000-0002-0298-351X

Historial editorial

Recibido: 28-abril-202I

Aceptado: IO-julio-202I

Publicado: 30-julio-202I

ISSN-e: 2594-2956 
En el presente trabajo se presenta el libro Formación docente en Chihuahua, I824-I940 desde una metodología de análisis crítico, donde la autora, la Dra. Esther Soto Pérez, realiza una consulta de gran variedad de fuentes de primera mano y -con la misma rigurosidad científica- se sirve también de fuentes secundarias, para abordar la formación de maestros en los periodos colonial, independiente y posrevolucionario. En primero, Soto aborda los aspectos de la Ilustración y del Positivismo y en periodo posrevolucionario, de 1936 a 1940, se trata la educación socialista. Entre cada uno de los modelos educativos se dan cambios. Soto analiza estos cambios, que constituyen sendas reformas. Cada gobierno usa la educación como la mejor vía para la realización de su proyecto de Estado y el ejecutor concreto de la educación es el maestro, quen pasa a ser el instrumento real de las reformas.

García Márquez (2002) escribe: "La vida no es la que uno vivió, sino la que uno recuerda y cómo la recuerda para contarla”. Pero buscar lo que fue y no lo que nosotros quisiéramos que hubiera sido, es la tarea del historiador. Para los comentadores, el texto queda totalmente suyo: Puede acercarse a los hechos pasados para urgirlos con los presentes. De ahí las siguientes preguntas: ¿De qué manera, el estudio de los procesos en el desarrollo histórico, se han implicado en el acontecer de las distintas y lejanas tierras del México multi-regional?, ¿de qué manera suceden en Chihuahua los acontecimientos tradicionalmente llamados nacionales?, ¿cómo se considera la función de los profesores en las reformas?, las huelgas de los profesores, ¿son invenciones actuales?

El relato Formación docente en Chihuahua, I824-1940, con un lenguaje claro y fluido, se vuelve alegre, "contando acontecimientos, relatando hechos, explicando contextos, deduciendo razones de ser, aventurando utopías, describiendo horizontes, resaltando sucesos" (Soto, 20I6, p. II). Y así, desde el centro de México, hasta el lejano Chihuahua, aparecen preclaros educadores, los estadistas que los trajeron y los docentes de lugares recónditos del estado, que gastan su vida en el anonimato. 
En el año de I824 Chihuahua inició como estado libre, al separarse de Durango, en la antigua Nueva Vizcaya, a tres años de la declaración de independencia. La historia crítica descubre ya el funcionalismo de la educación y la misma autora la concibe como:

[...] uno de los instrumentos que utiliza el Estado para alcanzar el modelo de sociedad al que aspira, por la vía de la racionalidad, la ideología, la cultura, la construcción de saberes, haceres y valores para que cada persona funcione en la sociedad de su tiempo (Soto, 20I6, p. 9).

La Dra. Soto hurga en las escuelas normales, escudriña conferencias y cartas, analiza planes de estudio, escuelas modelo, proyectos educativos, salarios de los maestros, documentos diversos, eventos culturales, sociales, económicos y políticos, que suceden en los innumerables recovecos de las prácticas escolares. La historia crítica empapa de diálogo todo el estudio, los historiadores "discuten, confrontan, aportan y cuestionan el análisis que se hace de los hechos pasados y presentes (Soto, 20I6, p. 39).

La autora investiga la implementación de las líneas educacionales a nivel federal y de ahí ensaya lo que sucede en Chihuahua en tres momentos históricos: La Colonia, el México Independiente -con la Ilustración y el Positivismo- y la educación socialista, ¿cómo se dieron estos cambios?

\section{La Colonia}

La educación colonial asumió el carácter de una cruzada religiosa, que perduró hasta muy entrado el siglo XX. Resabios del medioevo teocéntrico, el paraíso al que se llega por la luz de la fe; se estudia la teología y la religión. El positivismo y la ilustración, ofrecen el paraíso en la tierra, su puerta de acceso es la ciencia, en la escuela, a la luz de la razón. 


\section{El México independiente}

En I82I, México logra la independencia de España, define su proyecto de nación en la Constitución de I824, la educación se convierte en el vehículo para promover este proyecto de nación y los profesores, los responsables de su ejecución. Así, Soto (20I6) escribe, "es a los profesores a quienes se les reconoce un papel clave en las reformas educativas" (p. 48).

El Coronel José de Urquidi construye escuelas en todos los municipios y la Escuela Principal en la capital del estado. Las dificultades de los profesores encontraron sus espacios plagados de conflictos: luchas por el poder entre grupos, guerra entre apaches y hacendados, entre terratenientes y dueños de las minas, Intervención norteamericana y francesa.

\section{La Ilustración y el liberalismo}

El siglo XVIII, siglo de las luces, se caracteriza "por la crítica a las instituciones tradicionales y por su confianza en la razón (Soto, 20I6, p. I25). Sin embargo, la educación pública nace con el liberalismo, en las leyes del 2I al 23 de octubre de I833, expedidas por Valentín Gómez Farías. José María Luis Mora crea la Dirección de Instrucción Pública y se decreta la libre enseñanza.

Los caudillos independentistas eran ilustrados y, en el México libre, la ilustración se revistió de liberalismo: libertad de expresión, de creencias, de elegir autoridades y de comercio. En ese mismo año-I833se suprime la Universidad de México. Hecho símbolo de la reforma liberal "se sustrajo de las manos del clero [a la universidad] para fundamentarla en los conocimientos científicos avanzados" (Soto, 2016, p. 57). En I 857 la separación Iglesia-Estado se hace ley constitucional y las escuelas atendidas entonces por religiosos, pasan al Estado.

El lema: "orden y progreso" es la política de Porfirio Díaz, que conjuga la experimentación con las necesidades sociales. 
El paso de la ilustración al Positivismo, el sustento normativo, filosófico y pedagógico se desprendió de las leyes de Reforma publicadas en I857 y por la primera ley de instrucción pública, emanada de la misma constitución y que impulsaron otro paradigma educativo (Soto, 20I6, p. I25).

\section{El Positivismo en México}

La implementación de la educación positivista se llevó a cabo con muchos apuros económicos, en el año I885, en el municipio de Chihuahua, el gasto para pago a los profesores fue de II,645.02, el 49.6\% del total destinado a la educación. Ya desde entonces se usaba este tipo de chantaje social.

Las Conferencias pedagógicas fueron, de alguna manera, el antecedente de las Escuelas Normales, hasta que en I893 queda totalmente establecida con su director, Enrique Laubscher. En 1906 se establecieron las Escuelas: Industrial para señoritas, de Artes y Oficios, Comercial y la de Agricultura "Hermanos Escobar" (Soto, 2016, p. I37).

\section{La Educación socialista}

Don Lázaro Cárdenas busca darle sentido al Artículo $3^{\circ}$ de la Constitución de 1917 y quiso llevar a la práctica las promesas de la Revolución mexicana. Asume como proyecto de nación al socialismo y a la educación como su instrumento para implementarlo.

Soto (20I6) escribe: "El proyecto de educación socialista tenía como objetivo la desaparición del régimen capitalista para fundar una sociedad sin clases” (p. 156), ¿de qué forma percibieron su misión los maestros? Para construir esta sociedad sin clases los profesores tenían que asumir funciones de liderazgo capaces de organizar al proletariado rural y urbano, defender sus intereses, concientizarlos de su papel en la lucha de clases en contra de la explotación burguesa, simplemente, el maestro debía buscar un bienestar mayor para todos. En un relato sumamente dramático, Soto (2016) describe las zozobras de los profesores: 
como servidores públicos que debían adaptar sus actividades a la doctrina socialista sin tener una preparación previa, sufrieron de inmediato el ataque público por sus incipientes enseñanzas y revivieron los días de la lucha cristera, pero esta vez las víctimas solo fueron los maestros (p. 83).

Y es que el carácter socialista de la educación exigía de los profesores una inmensa variedad de actividades sociales: asambleas, festivales, manifestaciones, organización de comités, clubes, comisiones para gestionar servicios públicos, consejos técnicos para planear la docencia, maniobras de enseñanza militar para alumnos de grados superiores, talleres. Sólo les faltaba la evaluación y un reloj checador.

Pero el problema principal fue que los maestros, coherentes con la postura socialista, asumieron los problemas de sus comunidades:

algunos radicalizaron sus enseñanzas por lo que en muchos casos fueron asesinados o mutilados; hubo maestras violadas; casas y aulas incendiadas, y no siempre por la causa socialista, sino por la oposición que presentaba ante los abusos de los caciques, terratenientes y políticos del medio rural [...] Los maestros se enfrentaron a problemas e injusticias locales, y resultaron víctimas de su entrega a una lucha que ellos no habían provocado (Soto, 2016, p. 83).

\section{Conclusiones}

I. El libro de Soto (20I6) presenta un estudio sincrónico de la historia nacional con la chihuahuense. Se va contextualizando el acontecer estatal en el nacional; el resultado es genial, se nos presenta un marco cargado de realismo.

2. El personaje principal, es el maestro, el artífice de los cambios en la obra educativa total. El maestro es una persona importante y clave; pero una inmensa loza pesa sobre sus espaldas, ¿a cambio de qué?, ¿de que él también pudiera ser el culpable de los fracasos del sistema nacional? 
3. El sueldo del profesor no era muy generoso, 200 pesos anuales y muchas veces no les llegaban a tiempo; más bajo que el de los policías (Soto, 20I6) y si por la captura de un apache, la recompensa era de 200 pesos muerto y vivo 250 pesos, "es posible que más de un profesor estuviera tentado en abandonar el aula y su pago anual para obtener 200 pesos por asesinar un apache (p. IIO).

4. Los cambios en los sistemas educativos de la Ilustración al Positivismo y de este al Socialismo, llevaban al profesor a grandes apuros; pero presenta el grave problema de que los profesores estaban urgidos a beberse esos cambios. No estaban preparados para eso, lo que entorpecía la implementación de las reformas y atormentaba la vida del profesor.

5. ¿Qué tan importante es el estudio de las políticas educativas desde sus orígenes?, ¿qué se les puede decir a los maestros y a los historiadores? Este libro es útil para iniciar al nobel profesor en el estudio de las políticas educacionales.

\section{Referencias}

García Márquez, G. (2002). Vivir para contarla. México: Editorial Norma. Epígrafe.

Soto Pérez, E. (2016). Formación docente en Chihuahua I824-I940 [Colección Textos Universitarios n. I24]. Chihuahua, México: Sindicato del Personal Académico de la UACH / Universidad Autónoma de Chihuahua.

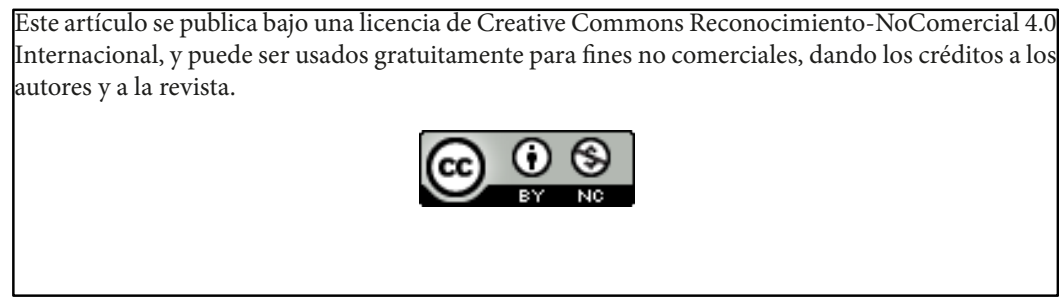

